Document downloaded from:

http://hdl.handle.net/10251/99742

This paper must be cited as:

Presenda-Barrera, A.; Salvador Moya, MD.; Penaranda-Foix, FL.; Catalá Civera, JM.; Pallone, E.; Ferreira, J.; Borrell Tomás, MA. (2017). Effects of microwave sintering in aging resistance of zirconia-based ceramics. Chemical Engineering and Processing Process Intensification. 112:404-412. doi:10.1016/j.cep.2017.03.002

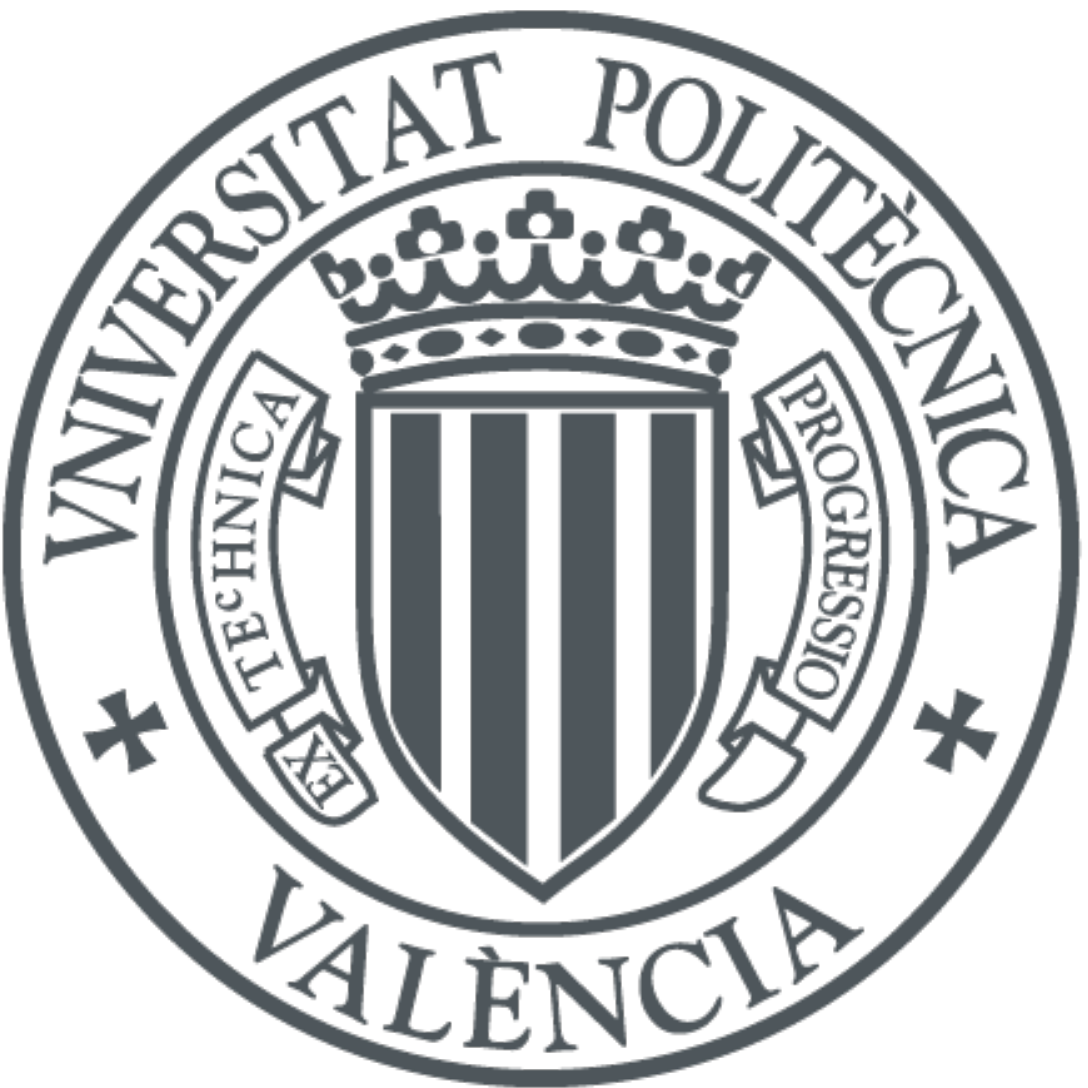

The final publication is available at

http://doi.org/10.1016/j.cep.2017.03.002

Copyright Elsevier

Additional Information 


\title{
EFFECTS OF MICROWAVE SINTERING IN AGING RESISTANCE OF ZIRCONIA-BASED CERAMICS
}

\author{
Álvaro PRESENDA ${ }^{1}$, María Dolores SALVADOR ${ }^{1}$, Felipe L. PENARANDA-FOIX ${ }^{2}$, \\ José M. CATALÁ-CIVERA², Eliria PALLONE ${ }^{3}$, Julieta FERREIRA³, Amparo \\ BORRELL ${ }^{1}$
}

${ }^{1}$ Instituto de Tecnología de Materiales, Universidad Politécnica de Valencia, Camino de Vera s/n, 46022, Valencia, SPAIN

${ }^{2}$ Instituto ITACA, Universidad Politécnica de Valencia, Camino de Vera, s/n, 46022 Valencia, SPAIN; e-mail: fpenaran@dcom.upv.es

${ }^{3}$ Universidade de São Paulo-FZEA, Avenida Duque Caxias Norte 225, 13635-900 Pirassununga, SP, BRASIL

\begin{abstract}
Innovative techniques for materials processing that result in shorter times and lower energy consumption than conventional methods, such as microwave sintering, are currently under investigation in order to obtain fully-consolidated ceramic materials. Microwave sintering has important effects on the resulting properties of zirconia-based ceramics, which, in turn, affect its performance and durability, as in the case of their susceptibility to low temperature hydrothermal degradation (LTD), an ageing phenomenon that deteriorates their mechanical performance. The purpose of this work consists on assessing the effects of microwave sintering on the microstructure and mechanical performance of zirconia composites by comparing it to conventional
\end{abstract}


sintering. Resistance to LTD of 3Y-TZP-only materials has also been evaluated. The results obtained in this work suggest that microwave sintering can reduce processing times and sintering temperatures when compared to conventional sintering while still obtaining dense zirconia-based ceramics and complying with the expected mechanical properties. At the same time, an increase in the resistance to LTD is also observed.

Keywords: Microwave sintering; Zirconia-based ceramics; Low-temperature degradation; Alumina-zirconia composites

\section{INTRODUCTION}

Zirconia $\left(\mathrm{ZrO}_{2}\right)$ ceramics have become widely studied as a consequence of their outstanding mechanical properties, such as hardness, mechanical strength and fracture toughness, which allow them to cover a wide spectrum of applications as structural ceramics, including the field of biomaterials [1,2]. Zirconia materials are commonly stabilized with low ytrria $\left(\mathrm{Y}_{2} \mathrm{O}_{3}\right)$ contents, ranging from $1.5-3.5 \mathrm{~mol} \%$, in what is known as yttria-stabilized tetragonal polycrystalline zirconia (Y-TZP) ceramics. The stabilization of the tetragonal (t) phase is responsible for such superb mechanical performance due to the transformation toughening mechanism that takes place. This mechanism consists of the spontaneous martensitic transformation of the metastable tphase to the room-temperature stable monoclinic (m) configuration as a crack propagates through the material. The transformed particles surround and enclose the crack inhibiting its growth [3]. Therefore, it is very important that the material is completely stabilized in the t-phase. In order to further improve the characteristics of t-stabilized zirconia ceramics, zirconia-based composites have been developed. Particularly, the addition of zirconia as a second phase to an alumina $\left(\mathrm{Al}_{2} \mathrm{O}_{3}\right)$ ceramic matrix combines the excellent hardness of $\mathrm{Al}_{2} \mathrm{O}_{3}$ with the high fracture toughness of $\mathrm{ZrO}_{2}$ resulting in a material with 
enhanced mechanical behavior [4]. These materials are collectively known as ZirconiaToughened-Alumina (ZTA) composites. Moreover, a composite configuration of a $\mathrm{ZrO}_{2}$ matrix with $\mathrm{Al}_{2} \mathrm{O}_{3}$ acting as the dispersed phase is also possible, giving place to materials known as Alumina-Toughened-Zirconia or ATZ.

The advantageous t- to m-phase transformation of 3Y-TZP ceramics responsible for toughening can also become counterproductive when the material is exposed to humid environments at temperatures of $20-300{ }^{\circ} \mathrm{C}$, due to a hydrothermal ageing phenomenon known as low-temperature hydrothermal degradation (LTD) [5,6]. The t-m transformation is accompanied by a change in volume that results in the introduction of defects in the material such as surface uplifts and microcracks [7]. As a consequence, surface roughening and microcracking arises and the mechanical and aesthetic properties are affected [8]. Therefore, it is extremely important to investigate the susceptibility of 3Y-TZP materials to LTD, especially when it comes to microstructure and mechanical properties. There are other factors that also affect the LTD behavior of zirconia materials including grain shape and size, stabilizer content and distribution, cubic phase content, porosity, and effect of residual stresses [9-11]. In general, these factors are directly influenced by the consolidation method employed to produce the resulting bodies from starting materials, which are usually powder-based. Solid-state sintering is a very common processing technique in ceramic engineering that requires high temperatures and, hence, a substantial amount of energy consumption in order to trigger the diffusion mechanisms that allow for densification of compacted powder bodies.

For that matter, non-conventional sintering methods are under investigation as they can modify sintering mechanisms that result in changes in the microstructure and phase composition of the consolidated materials, while, at the same time, reduce processing times and energy consumption. One such approach is microwave heating technology. 
Microwave heating consists of the absorption of electromagnetic radiation by materials due to their intrinsic dielectric properties [12,13]. Ceramic materials such as 3Y-TZP are able to absorb microwave radiation due to the presence of molecular dipoles [12]. These dipoles interact with the oscillating electric field induced by microwaves by rotating continuously in order to align with the field. Molecular resistance to these rotations generates heat, increasing the material's temperature, a process known as dielectric heating [14]. Several authors [15-18] have determined that highly dense materials without substantial grain coarsening may be obtained with microwave sintering since dwell times are considerably shortened and heating rates can be substantially increased. In some studies, lower sintering temperatures have been applied while obtaining materials with relative densities comparable to those of conventional sintering at higher temperatures $[19,20]$. As 3Y-TZP materials with a finer microstructure and a high degree of densification can be obtained, mechanical properties may be enhanced, improving the overall quality of the resulting material [16]. The modified microstructure that results from microwave sintering is very likely to affect the behavior of 3Y-TZP materials against hydrothermal degradation. Moreover, shortening dwell times and lowering sintering temperatures reduce the amount of energy consumption during the process.

The purpose of this study is to investigate the sinterability via microwave heating technology of 3Y-TZP-based ceramics, including ZTA composites with three different concentrations (5, 10 and 15 vol\% $\mathrm{ZrO}_{2}$ ) and an ATZ (5 vol\% $\mathrm{Al}_{2} \mathrm{O}_{3}$ ) composite, and the resulting mechanical properties and microstructure. Additionally, the effect of microwave sintering on LTD susceptibility of 3Y-TZP materials is also evaluated. Conventional sintering is used for reference purposes. Assessment of LTD degradation is performed by analyzing induced phase transformation, surface roughening and crack propagation.

\section{MATERIALS AND METHODS}


The experimental procedure is divided in three parts. In the first part, the mechanical properties and microstructure of ZTA composites at different concentrations of $\mathrm{ZrO}_{2}$ sintered via microwaves are investigated and compared to those obtained by conventional sintering. In this case, a commercial 3Y-TZP powder from Tosoh containing $3 \mathrm{~mol} \%$ yttria has been employed after deagglomeration in a carefully-prepared colloidal suspension. The preparation procedure of this powder can be found in Reference [21]. The concentrations of the composites are 5 vol\% 3Y-TZP/95vol\% $\mathrm{Al}_{2} \mathrm{O}_{3}$ (5ZTA), 10 vol\% $3 \mathrm{Y}-\mathrm{TZP} / 90$ vol\% $\mathrm{Al}_{2} \mathrm{O}_{3}$ (10ZTA), and 15 vol\% 3Y-TZP/85 vol\% $\mathrm{Al}_{2} \mathrm{O}_{3}$ (15ZTA). Additionally, a 95 vol\% $3 \mathrm{Y}-\mathrm{TZP} / 5$ vol\% $\mathrm{Al}_{2} \mathrm{O}_{3}$ (5ATZ) has also been processed. The starting materials are powder-based mixtures. The second part consists of a LTD study of 3Y-TZP materials in order to investigate the effect of microwave sintering on the resistance to LTD by comparing it to conventional sintering. The third part consists on a study regarding crack propagation in degraded and non-degraded 3Y-TZP material to show the importance of resistance to LTD.

For the ZTA composites, microwave sintering conditions were as follows: 1300 and $1400{ }^{\circ} \mathrm{C}, 10 \mathrm{~min}, 100{ }^{\circ} \mathrm{C} / \mathrm{min}$ for final dwell temperatures, dwell time and heating rate, respectively. Conventional sintering was carried out at $1400{ }^{\circ} \mathrm{C}, 2 \mathrm{~h}$ and $10^{\circ} \mathrm{C} / \mathrm{min}$. All specimens were sintered in air. These selected parameters are based on previous studies in our research group, where sintering conditions were optimized for 3Y-TZP-based materials $[16,20,22]$. For the full 3Y-TZP material, microwave sintering was carried out at 1200 and $1300{ }^{\circ} \mathrm{C}$, keeping the other sintering parameters as in part one, and conventional sintering was performed under the same conditions as in part one. A lower temperature has been selected because zirconia requires lower sintering temperatures with respect to alumina-containing materials. 
Conventional sintering (CS) was performed in an electrical furnace (Thermolyne type 46100, USA). Microwave (MW) heating technology has been employed as a nonconventional sintering technique. In this case, samples were introduced in a mono-mode (2.45 GHz) rectangular cavity that is automatically adjusted to optimize microwave absorption and control the heating rate. The configuration of the microwave system is shown in Figure 1. A variable power output from $0 \mathrm{~W}$ to $1200 \mathrm{~W}$ is possible. In this case, the power has been set to $700 \mathrm{~W}$.

Sample characterization in the first part consisted of carrying out Vickers hardness, $H$, and fracture toughness, $K_{I C}$, measurements via microindentation methods with a Shimadzu HMV-20 Vickers indenter. A total of five samples for each condition were measured. Relative density has been determined following ASTM-C-373 and using the corresponding theoretical density values. Analysis of the microstructure was performed with Field Emission Scanning Electron Microscopy (FE-SEM, S4800 Hitachi, Japan). Average grain size has been measured for 100 grains using the linear-intercept method with the Image-Pro Plus image analysis program. 


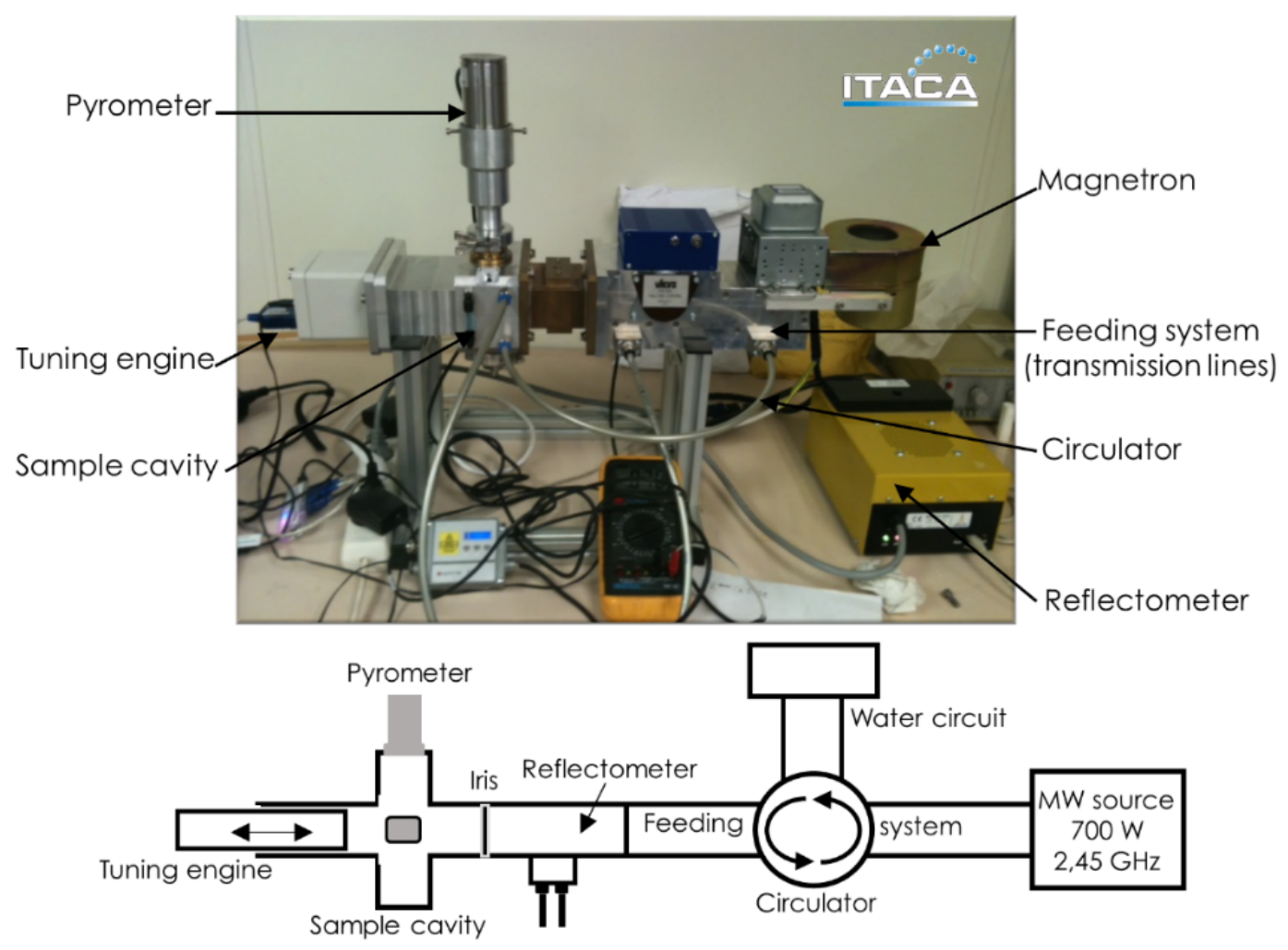

Fig. 1. Microwave system setup for sintering of 3Y-TZP ceramics.

Characterization of the second part consisted of the evaluation of mechanical properties, phase content change and penetration of transformed layer as a function of LTD exposure time. Specimens are mirror polished and autoclaved in steam at $125{ }^{\circ} \mathrm{C}$ and $1.6 \mathrm{bar}$. Characterization of aged samples is performed after every $20 \mathrm{~h}$ of exposure to LTD conditions until $200 \mathrm{~h}$ treatment is reached. Mechanical properties, such as $H$ and elastic modulus, E, were determined with the nanoindentation technique (G-200, Agilent Technologies, USA) using the Continuous Stiffness Measurement (CSM) technique. Xray diffraction (XRD) has been performed with an XRD 3003-TT (Seifert, Ahrensburg, Germany) using $\mathrm{Cu} \mathrm{K} \alpha$ radiation at $40 \mathrm{kV}$ and $40 \mathrm{~mA}$ in pre-sintered and sintered specimens, as well as after $200 \mathrm{~h}$ of LTD exposure. Rietveld refinement of X-ray diffractograms monoclinic, tetragonal and cubic (c) phases. Phase content analysis was also assessed with a micro-Raman spectrometer (LabRam HR UV, HORIBA Jobin Yvon, France) coupled with a thermoelectrically-cooled multichannel CCD detector after every 
20 h of LTD exposure. Raman spectra has been recorded for a Raman shift range from $120-700 \mathrm{~cm}^{-1}$. An average of two successive measurements, each with an integration time of 2 min, has been performed to obtain a well-defined spectrum. A laser wavelength of $532 \mathrm{~nm}$ (green laser) through a 509 objective with a lateral resolution of approximately $2 \mu \mathrm{m}$ has been employed. For quantification of m-phase volumetric content, the equation proposed by Lim et al. [23] using the intensity of the peaks indicated by the superscript was employed:

$$
V_{m}=\frac{I_{m}^{181}+I_{m}^{190}}{0.33\left(I_{t}^{147}+I_{t}^{265}\right)+I_{m}^{181}+I_{m}^{190}}
$$

where:

$V_{m}=$ m-phase volume fraction

$I=$ integrated peak intensity (area under peak)

$m, t=$ subscript referencing the $m$ - and $t$-phase, respectively

FE-SEM images of the transversal section of degraded layers were also obtained to determine the depth of the degraded layer and evaluate the changes in microstructure. Additionally, Focused Ion Beam (FIB, Auriga Compact, ZEISS, Germany) was utilized to examine the sub-superficial propagation of cracks in degraded and non-degraded material to emphasize the importance of LTD resistance. Samples have been prepared by depositing a carbon layer on the surface to obtain a conductive sample. A dual FIB/SEM system has been employed. A trench was dug with the FIB perpendicular to the direction of the crack generated by indentation, while the SEM system allowed for imaging of the sub-superficial zone beneath the crack.

\section{RESULTS AND DISCUSSION}

\subsection{Microwave sintering and characterization of zirconia-based composites}


The processing time for MW-sintered specimens amounted to $30 \mathrm{~min}$, accounting also for the time required to reach the final dwell temperature, while conventional sintering required a total of $350 \mathrm{~min}$. Moreover, energy consumption has also been reduced significantly. Conventional sintering requires a considerable amount of energy not only to heat the sample but also to heat up all the elements in the furnace (walls, air, thermocouples to measure temperature) in order to reach the dwell temperature. Conductive and convective heat losses occur wasting energy as dissipated heat. Additionally, since the dwell times are more prolonged, the amount of energy necessary for processing the materials increases too. The energy is directly absorbed by the sample in microwave sintering due to the effect of dielectric heating, reducing heat losses associated with conduction and convection. In this sense, microwave sintering can be regarded as an advantageous processing technique over conventional methods. It is still important to consider, however, that currently systems only allow for the processing of individual specimens.

The sintering conditions and characterization results obtained for MW and CS specimens are summarized in Table 1. The degree of the densification of the composites is measured in terms of relative density. The values of composites for MW sintering at $1300{ }^{\circ} \mathrm{C}$ show that this temperature might not be sufficient to reach theoretical density values close to $100 \%$ since they are approximately around $95 \%$. At $1400{ }^{\circ} \mathrm{C}$ in both $\mathrm{MW}$ and $\mathrm{CS}$ relative density is between 98 and $99 \%$, indicating a better densification of the materials at this temperature with MW sintering resulting in a slightly higher relative density value. The influence of $\mathrm{Al}_{2} \mathrm{O}_{3}$ content is also important because $\mathrm{Al}_{2} \mathrm{O}_{3}$ requires higher sintering temperatures than $\mathrm{ZrO}_{2}$. As a consequence, the relative density values of composites with higher $\mathrm{Al}_{2} \mathrm{O}_{3}$ percent are lower than in composites with lower $\mathrm{Al}_{2} \mathrm{O}_{3}$ amounts. Such behavior occurs in both conventional and microwave sintering. When comparing relative 
densities between microwave and conventionally sintered samples at the same sintering temperature, MW sintering results have slightly higher relative density values in all three different composites. In the 5ATZ composite, increasing relative density values have also been observed.

Table 1. Sintering conditions, density and mechanical properties obtained for the ZTA and ATZ composites and 3Y-TZP materials under different sintering conditions.

\begin{tabular}{|c|c|c|c|c|c|c|}
\hline Material & $\begin{array}{c}\text { Sintering } \\
\text { method }\end{array}$ & $\begin{array}{c}\text { Sintering } \\
\text { temperature } \\
\left({ }^{\circ} \mathrm{C}\right)\end{array}$ & $\begin{array}{l}\text { Dwell } \\
\text { time } \\
\text { min }\end{array}$ & $\begin{array}{c}\text { Density } \\
\text { (\%) }\end{array}$ & $\begin{array}{c}\text { Vickers } \\
\text { hardness } \\
\text { (GPa) }\end{array}$ & 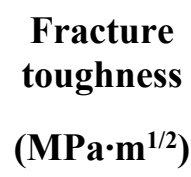 \\
\hline \multirow{3}{*}{15 ZTA } & \multirow{2}{*}{ MW } & 1300 & 10 & $96.4 \pm 0.5$ & $13.1 \pm 1.0$ & $5.2 \pm 0.5$ \\
\hline & & 1400 & 10 & $98.9 \pm 0.4$ & $17.9 \pm 0.7$ & $5.9 \pm 0.4$ \\
\hline & $\mathrm{CS}$ & 1400 & 120 & $98.3 \pm 0.4$ & $16.7 \pm 0.6$ & $6.1 \pm 0.3$ \\
\hline \multirow{3}{*}{$10 \mathrm{ZTA}$} & \multirow{2}{*}{ MW } & 1300 & 10 & $94.1 \pm 0.4$ & $14.1 \pm 0.8$ & $4.3 \pm 0.5$ \\
\hline & & 1400 & 10 & $99.2 \pm 0.5$ & $19.8 \pm 0.5$ & $5.3 \pm 0.4$ \\
\hline & $\mathrm{CS}$ & 1400 & 120 & $98.2 \pm 0.5$ & $19.6 \pm 0.6$ & $5.6 \pm 0.3$ \\
\hline \multirow{3}{*}{5 ZTA } & \multirow{2}{*}{ MW } & 1300 & 10 & $92.4 \pm 0.4$ & $12.6 \pm 0.9$ & $4.0 \pm 0.5$ \\
\hline & & 1400 & 10 & $98.9 \pm 0.3$ & $19.3 \pm 0.5$ & $4.4 \pm 0.4$ \\
\hline & $\mathrm{CS}$ & 1400 & 120 & $98.6 \pm 0.3$ & $19.1 \pm 0.6$ & $3.3 \pm 0.3$ \\
\hline \multirow{3}{*}{$5 \mathrm{ATZ}$} & \multirow{2}{*}{ MW } & 1300 & 10 & $95.5 \pm 0.5$ & $12.7 \pm 0.7$ & $6.9 \pm 0.5$ \\
\hline & & 1400 & 10 & $98.5 \pm 0.4$ & $13.2 \pm 0.6$ & $6.2 \pm 0.6$ \\
\hline & $\mathrm{CS}$ & 1400 & 120 & $99.5 \pm 0.4$ & $13.8 \pm 0.5$ & $6.9 \pm 0.5$ \\
\hline \multirow{3}{*}{ 3Y-TZP } & \multirow{2}{*}{ MW } & 1200 & 10 & $99.5 \pm 0.5$ & $13.9 \pm 0.8$ & $6.6 \pm 0.4$ \\
\hline & & 1300 & 10 & $99.3 \pm 0.5$ & $14.7 \pm 0.6$ & $5.8 \pm 0.4$ \\
\hline & $\mathrm{CS}$ & 1400 & 120 & $99.1 \pm 0.5$ & $13.9 \pm 0.4$ & $6.5 \pm 0.5$ \\
\hline
\end{tabular}

Regarding mechanical properties, the results agree with the relative density values that have been calculated. Low relative density values result in lower hardness. At $1300{ }^{\circ} \mathrm{C}$, the hardness of the composites is quite low, which is expected for a ZTA composite, suggesting the effects of defects such as porosity are still significant. However, at 1400 ${ }^{\circ} \mathrm{C}$ hardness values are improved reaching values of $18 \mathrm{GPa}$ or more. MW at $1400{ }^{\circ} \mathrm{C}$ results in slightly higher hardness values than CS at the same temperature in all three ZTA composites. Hardness of the 5ATZ composite and 3Y-TZP is lower due to the lower 
content and absence of alumina, respectively, in these samples. Fracture toughness, on the other hand, results in higher values due to a higher content of t-zirconia, which provides the transformation toughening mechanism that inhibits crack propagation.

Processing affects the resulting microstructure, which, in turn, has a significant influence in the mechanical properties. Therefore, an analysis of the grain size and its variability and, in the case of composites, the distribution of second phases is fundamental. Figure 2 shows the microstructure of 5ZTA, 15ZTA and 5ATZ composites sintered via microwave heating at $1400{ }^{\circ} \mathrm{C}$ (Figure 2a, 2b and 2c, respectively), as well as those of 3Y-TZP sintered at $1300{ }^{\circ} \mathrm{C}$ (Figure 2d), and conventional sintered specimens of 5ZTA and 5ATZ (Figure 2e and 2f, respectively). In the micrographs, a high degree of densification of the materials can be observed for the selected sintering conditions as no significant porosity has been identified. The distribution of $\mathrm{ZrO}_{2}$ in the $\mathrm{Al}_{2} \mathrm{O}_{3}$ matrix in the ZTA composites is clearly distinguishable due to the color contrast in the image, where white grains represent $\mathrm{ZrO}_{2}$ embedded within the darker $\mathrm{Al}_{2} \mathrm{O}_{3}$ continuous phase. The higher $\mathrm{ZrO}_{2}$ of 15ZTA compared to 5ZTA is also clear, as more white grains can be observed in the 15ZTA composite. The grain size of zirconia is significantly smaller for MW-sintered specimens $(<0.3 \mu \mathrm{m})$ compared to conventional sintered counterparts $(>0.5 \mu \mathrm{m})$, as shown in Figures 2a and 2e, respectively, both corresponding to 5ZTA. In the case of 5ATZ, this behavior is more pronounced, as the grain size of zirconia is smaller for microwave sintering $(<0.3 \mu \mathrm{m})$ than for conventional sintering $(>0.6 \mu \mathrm{m})$. MW-sintered 5ATZ (Figure 2c) has a significantly smaller grain size than 5ATZ from conventional sintering (Figure 2f). The larger grain sizes in conventional sintered specimens are a consequence of the lower heating rates and longer dwell times required for full consolidation when compared to microwave sintering. In general, grain shapes tend to be 
equiaxial and slightly rounded, which is characteristic of these materials, for both sintering techniques.
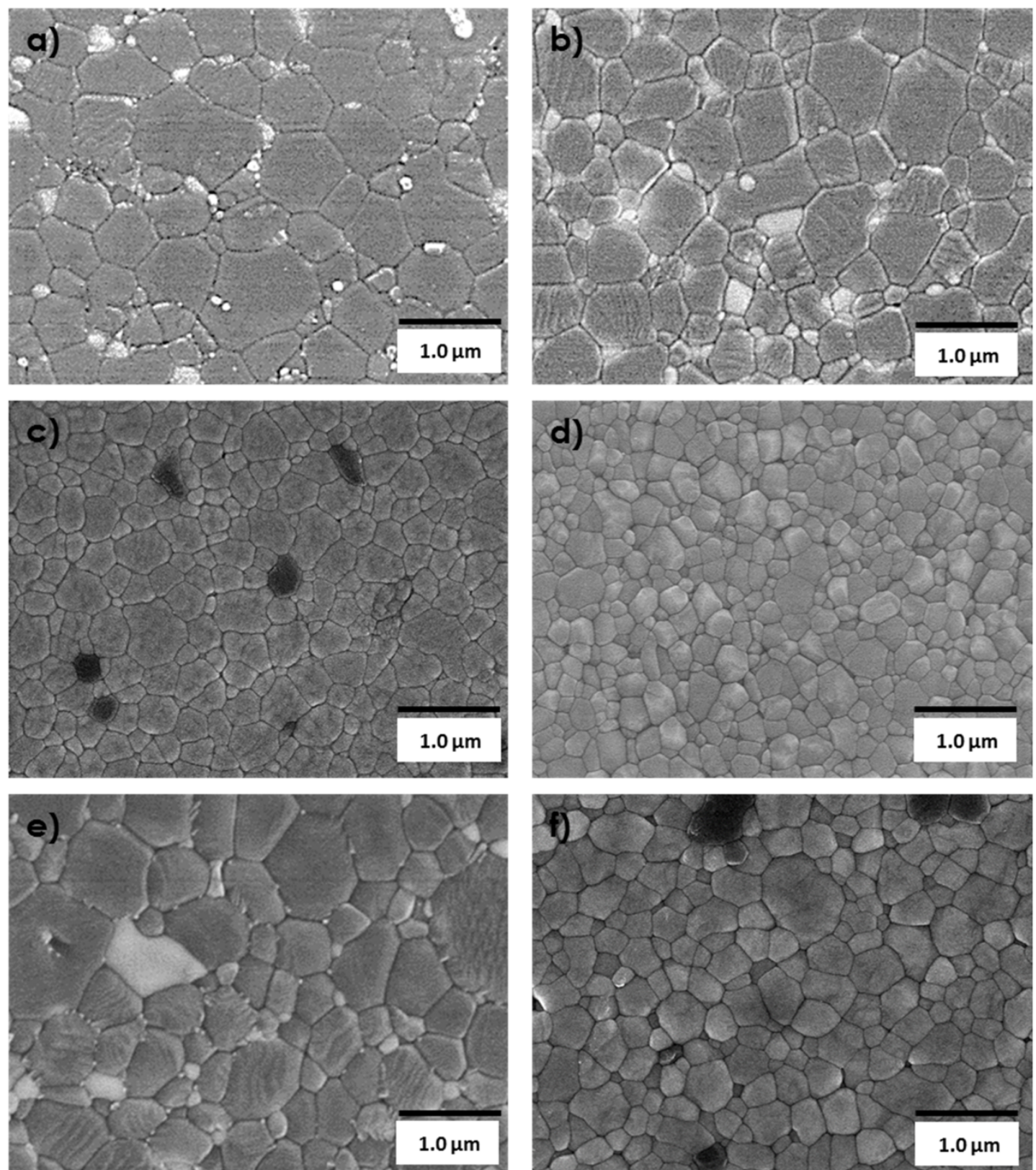

Fig. 2. FE-SEM images of microstructure of MW-sintered composites at $1400^{\circ} \mathrm{C}$ : a) $5 Z T A$,

b) $15 Z T A$, c) $5 \mathrm{ATZ}$ and d) $3 \mathrm{Y}-\mathrm{TZP}$ sintered at $1300^{\circ} \mathrm{C}$. Specimens processed by conventional sintering at $1400{ }^{\circ} \mathrm{C}$ are shown for e) 5ZTA and f) 5ATZ.

The 3Y-TZP material sintered at $1300{ }^{\circ} \mathrm{C}$ exhibits a microstructure with grain sizes ranging from 0.1 to $0.5 \mu \mathrm{m}$. However, already at $1200{ }^{\circ} \mathrm{C}$, a relative density above $99.5 \%$ has been achieved and the mechanical properties are comparable to those of CS at 1400 
${ }^{\circ} \mathrm{C}$. Zirconia requires lower processing temperatures than alumina containing materials, therefore, this selected temperature is high enough to obtain consolidated materials. The processing of different alumina and zirconia composites by microwave heating technology performed in this work indicate that this innovative consolidation technique can be used for a different ceramic materials. Moreover, the densification, mechanical properties and microstructure can be compared to those obtained by CS applying substantially shorter processing times, higher heating rates and requiring a lower energy consumption. The heating mechanisms involved in MW sintering of ceramic materials indicate that heat flow occurs from the inside of the material towards the surface, which contrasts with CS, where heat flows from the surface into the material bulk. Therefore, the sintering process is enhanced by triggering mass diffusion mechanisms simultaneously from the interior of thousands of grains and accelerating their coalescence, reducing significantly the overall processing time to achieve full densification. In contrast, the convective and conductive heat transfer mechanism in CS require heat to travel from grains located on the surface, then flowing through adjacent grains and so on requiring long dwell times, which can take up to several hours, so grains have enough time and energy to form bridges and coalesce to reach full densification.

\subsection{Low-temperature hydrothermal degradation behavior of microwave sintered 3Y-} TZP

In this section, the results obtained for the evaluation of the effect of MW sintering on the LTD behavior of the 3Y-TZP material are presented. A comparative study with CS has been carried out. The selected samples are MW-sintered 3Y-TZP at $1200{ }^{\circ} \mathrm{C}$ and CS at $1400{ }^{\circ} \mathrm{C}$ because, as can be observed in the previous section a high densification has been achieved under these conditions, as well as the resulting mechanical properties are very similar. Figure 3 includes a bar graph of monoclinic, tetragonal and cubic phase weight 
percent (wt\%) obtained from Rietveld refinement of X-ray diffractograms before sintering, upon sintering via MW and CS and after 200 h of LTD exposure. As can be observed, the content $\mathrm{t}-\mathrm{ZrO}{ }_{2}$ before sintering is above $65 \mathrm{wt} \%$, while $\mathrm{m}-\mathrm{ZrO}_{2}$ is around $20 \mathrm{wt} \%$ and $\mathrm{c}-\mathrm{ZrO}_{2}$ is $15 \mathrm{wt} \%$. As sintering takes place and the temperature is increased, $\mathrm{m}-\mathrm{ZrO}_{2}$ will transform into $\mathrm{t}-\mathrm{ZrO}_{2}$ and once it cools down, due to the presence of stabilizer, in this case $\mathrm{Y}_{2} \mathrm{O}_{3}$, the $\mathrm{t}-\mathrm{ZrO}_{2}$ phase will be maintained.

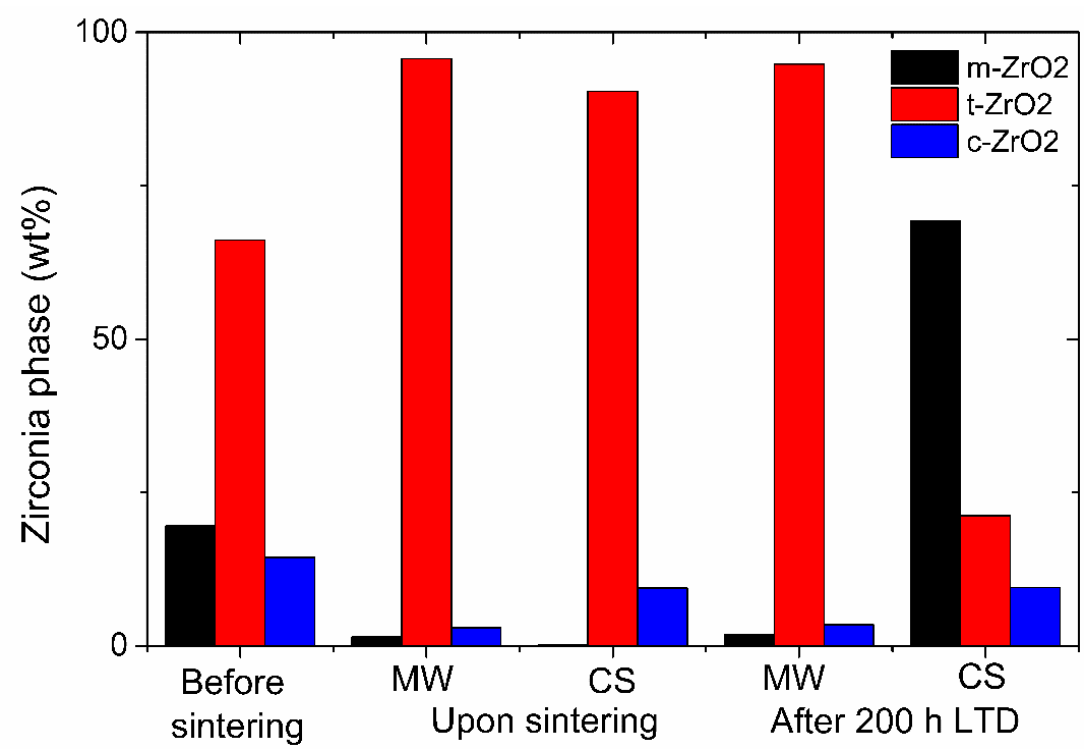

Fig. 3. Zirconia wt\% phase content obtained from Rietveld analysis of X-ray diffractograms for 3Y-TZP material before sintering, upon sintering and after 200 h of LTD exposure.

After sintering, differences in phase content arise due, primarily, to the sintering method employed. Particularly, the amount of $\mathrm{t}-\mathrm{ZrO}_{2}$ is higher for the $\mathrm{MW}$-sintered specimen than for CS. Additionally, the amount of c-phase is lower in the MW-sintered specimen. Such behavior can be attributed to the lower temperature employed in MW sintering. The $\mathrm{c}-\mathrm{ZrO}_{2}$ phase is stable at higher temperatures, therefore if a lower sintering temperature is employed, it is less likely that c- $\mathrm{ZrO}_{2}$ will occur in the resulting material. However, in $\mathrm{CS}$, where a higher sintering temperature has been employed, the amount of $\mathrm{c}-\mathrm{ZrO}_{2}$ is higher. 
After 200 h of LTD exposure, m-phase content has substantially increased in the CS sample, where an almost complete t-to-m transformation can be observed due to the effects of degradation. In contrast, the MW sample remains mostly untransformed, as there is only an almost imperceptible increase in $\mathrm{m}-\mathrm{ZrO}_{2}$ content from the sample upon sintering. The $\mathrm{t}-\mathrm{ZrO}_{2}$ is still above $90 \%$ indicating that a higher resistance to LTD has been achieved with MW sintering.

The presence of c-phase plays an important role in understanding the higher LTD resistance of microwave-sintered samples. At the selected conditions, CS increases cphase zirconia content, as can be observed in the values of $\mathrm{c}-\mathrm{ZrO}_{2}$. The presence of cubic zirconia accelerates the transformation of tetragonal to monoclinic phase, as tetragonal grains are depleted from $\mathrm{Y}_{2} \mathrm{O}_{3}$ due to the migration of the stabilizer into cubic grains [5]. As microwave sintering requires lower temperatures for the full consolidation of 3Y-TZP ceramics than conventional sintering, the amount of c-phase content is reduced and the resistance to LTD is enhanced.

In order to evaluate the progression of degradation, the volumetric m-phase content has been determined from Raman spectra as a function of LTD exposure time. Samples have been characterized at intervals of $20 \mathrm{~h}$ until reaching $100 \mathrm{~h}$, after $140 \mathrm{~h}$ and finally after $200 \mathrm{~h}$. The sintering method had an important influence on the volume fraction of mphase, $V_{m}$, calculated from the intensities of the Raman spectra, as it progressed at different rates in each sample, which can be seen in Figure 4. The MW-sintered sample shows an imperceptible vulnerability to m-phase transformation, while the conventionally sintered sample is definitely affected by LTD-induced transformation, as it already contains a $V_{m}$ of $30 \%$ after 40 h of hydrothermal degradation exposure, despite both samples having similar properties and microstructure. The presence of c-phase and untransformed t-phase $\mathrm{ZrO}_{2}$ provided by $\mathrm{X}$-ray diffraction phase quantification indicate 
that a maximum phase transformation amount has been reached in the material at this point.

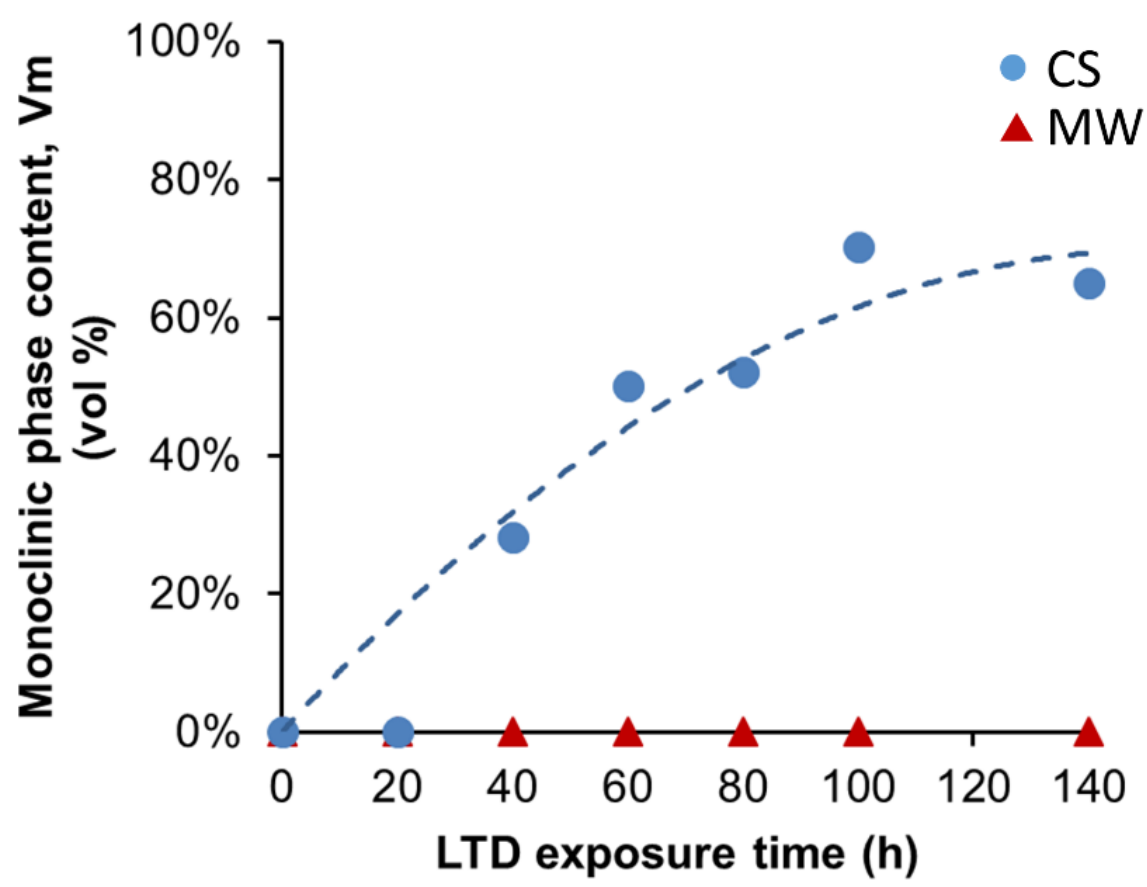

Fig. 4. Monoclinic phase content, $V_{m}$, evolution as a function of LTD exposure time in microwave and conventionally sintered 3Y-TZP.

In order to determine the penetration depth of the zirconia-transformed layer after $140 \mathrm{~h}$, FE-SEM images of transversally-cut samples have been obtained and are shown in Figure 5. The layer observed in the micrographs is a result of the grain detachment of the transformed zone that occurs during the polishing stage of sample preparation. Grains in the degraded zone that have expanded due to the volume change induced by phase transformation are pulled off from the material during the abrasive treatment resulting in an increase of porosity in this zone. As can be seen in the micrographs, the penetration depth of the transformed zone varies significantly depending on the sintering method. The MW-sintered sample shows a significantly higher resistance to degradation penetration with a transformed layer of less than $5 \mu \mathrm{m}$ than the CS sample, which results 
in a depth of almost $15 \mu \mathrm{m}$. The depth of the transformed layer is also important to understand the kinetics of LTD in zirconia materials. Even though the results from Raman spectroscopy indicate the absence of m-phase zirconia in MW-sintered material, the FESEM image reveal a very slight, sub-superficial degraded zone of less than $5 \mu \mathrm{m}$.
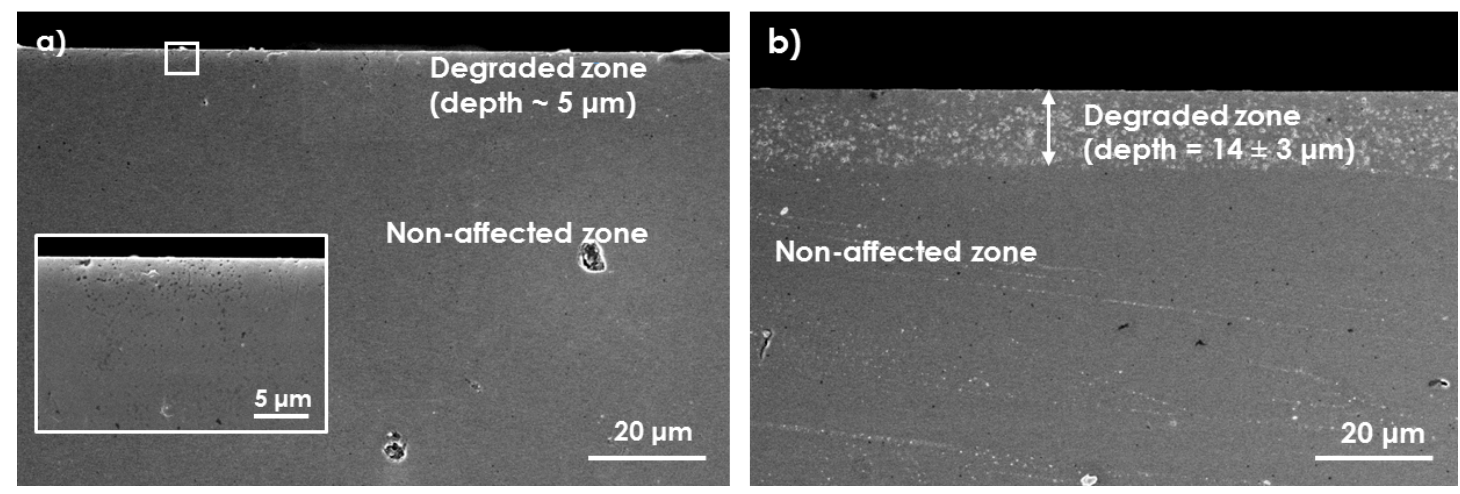

Fig. 5. FE-SEM micrographs of the degraded zone profiles after $140 \mathrm{~h}$ of LTD for 3 Y-TZP:

a) MW and b) CS.

In order to assess the quality of the material after exposure to LTD, two important mechanical properties, $\mathrm{E}$ and $\mathrm{H}$, have been determined as a function of hydrothermal degradation time. These properties are also affected by the sintering method that has been employed. The results for $\mathrm{E}$ and $\mathrm{H}$ of $3 \mathrm{Y}$-TZP material after conventional and microwave sintering as a function of LTD exposure time are summarized in Figure 6. The results corroborate the high resistance to LTD of the microwave sintered 3Y-TZP, as E and H remain almost unaffected. Even after $140 \mathrm{~h}$, E is still around $250 \mathrm{GPa}$ and $\mathrm{H}$ is approximately $15 \mathrm{GPa}$. The properties of the conventional sintered sample are, however, notably degraded as hydrothermal exposure time progresses. After $40 \mathrm{~h}$, the values of $\mathrm{E}$ and $\mathrm{H}$ of the conventionally sintered samples are considerably lower. When $80 \mathrm{~h}$ is reached, E has decayed almost one-third from the initial value. This suggests that a decrease of mechanical properties may occur faster during the first degradation stages.

In order to correctly interpret the values of $\mathrm{E}$ and $\mathrm{H}$ that have been calculated, it is important to consider the depth of penetration of the transformed zone. The indenter 
penetration depth was set at $2 \mu \mathrm{m}$ approximately. Therefore, during the initial degradation stages, where it is very likely that a combination of tetragonal and monoclinic zirconia can be found at such sub-superficial depth, the $\mathrm{E}$ and $\mathrm{H}$ values that have been determined depend on the amount of transformed zirconia and result from a combination of both phases.

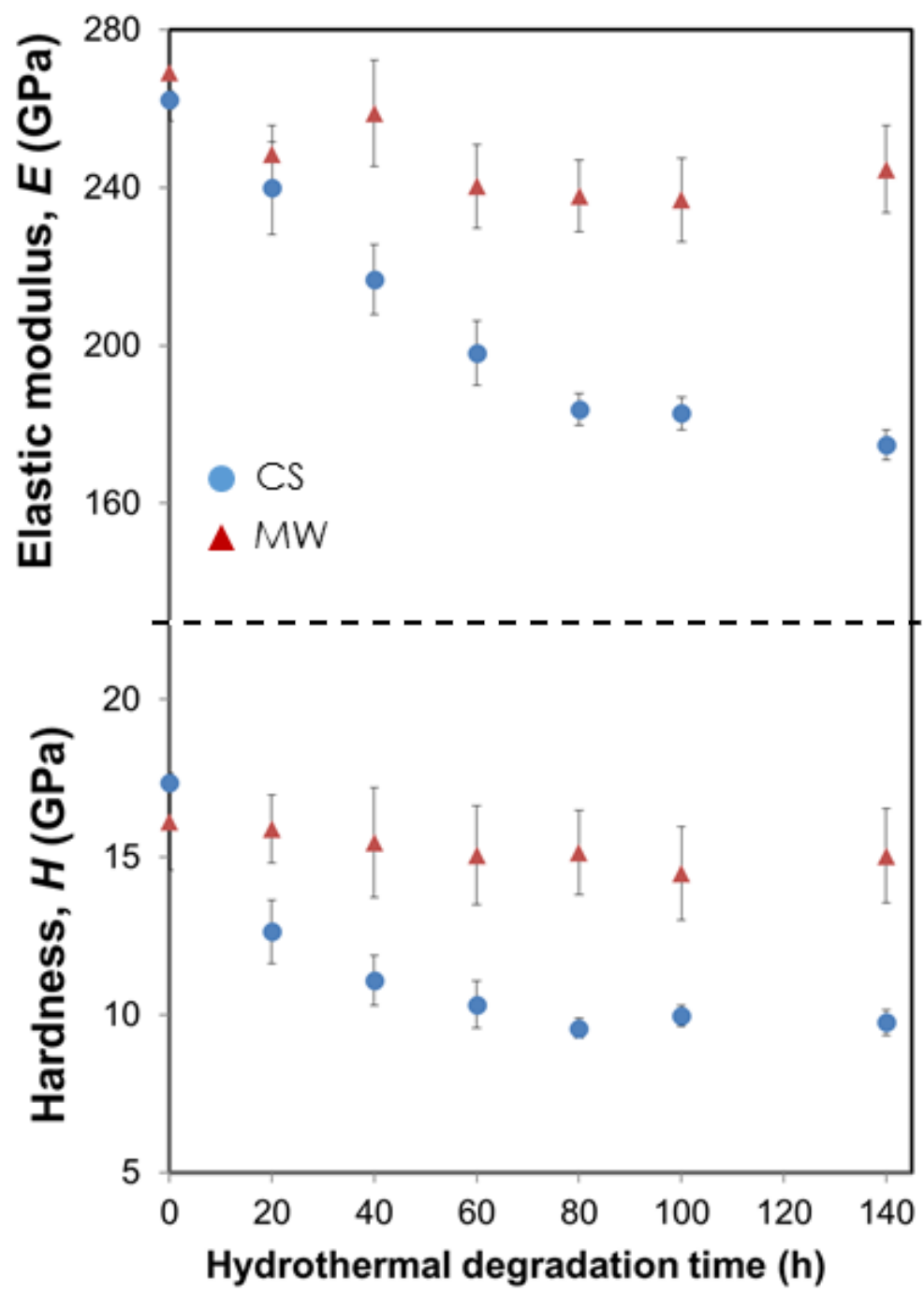

Fig. 6. Elastic modulus and hardness values of $3 \mathrm{Y}-\mathrm{TZP}$ material after conventional and MW sintering as a function of LTD exposure time.

Mechanical properties have been affected in such a way that when LTD exposure time is increased, E and $\mathrm{H}$ values decrease. Such effect on mechanical properties is extremely relevant since their high Young modulus and hardness values are one of the main reasons 
Y-TZP materials are considered for a wide spectrum of applications. LTD resistance of the microwave-sintered specimen is very high since no detectable m-phase transformation has occurred and mechanical properties are maintained even after $200 \mathrm{~h}$ of LTD exposure.

\subsection{Sub-superficial crack propagation in degraded and non-degraded 3Y-TZP materials}

The structural performance of 3Y-TZP dental materials is severely affected by the effects of LTD. Mechanical properties, such as hardness, fracture toughness, Young's modulus and mechanical resistance decrease significantly because $\mathrm{m}-\mathrm{ZrO}_{2}$ has lower values than $\mathrm{t}-\mathrm{ZrO}_{2}$ regarding these properties. In particular, fracture toughness, which inhibits crack propagation and prevents mechanical failure, is one of the most important reasons that have allowed 3Y-TZP ceramics find useful applications in many areas, being dentistry one of them.

FIB technology coupled with an FE-SEM system has been used to analyze the subsuperficial microstructure resulting from cracks induced by microindentation testing on degraded and non-degraded specimens. The microindentation tests have been performed on the specimens' cross section. The loads applied have been high enough to generate cracks at the corners of the imprint. In the case of the degraded material corresponding to CS, exposure to LTD has been $200 \mathrm{~h}$ in order to produce a layer deep enough for carrying out the microindentation test and the load applied has been $4.9 \mathrm{~N}$ (Figure 7). As can be seen in the micrograph, the imprint was created inside the degraded layer very close to the surface edge. For the non-degraded material, which corresponds to MW sintering, the load must be increased to $19.6 \mathrm{~N}$, so as to generate cracks of a comparable length to those in degraded material. 


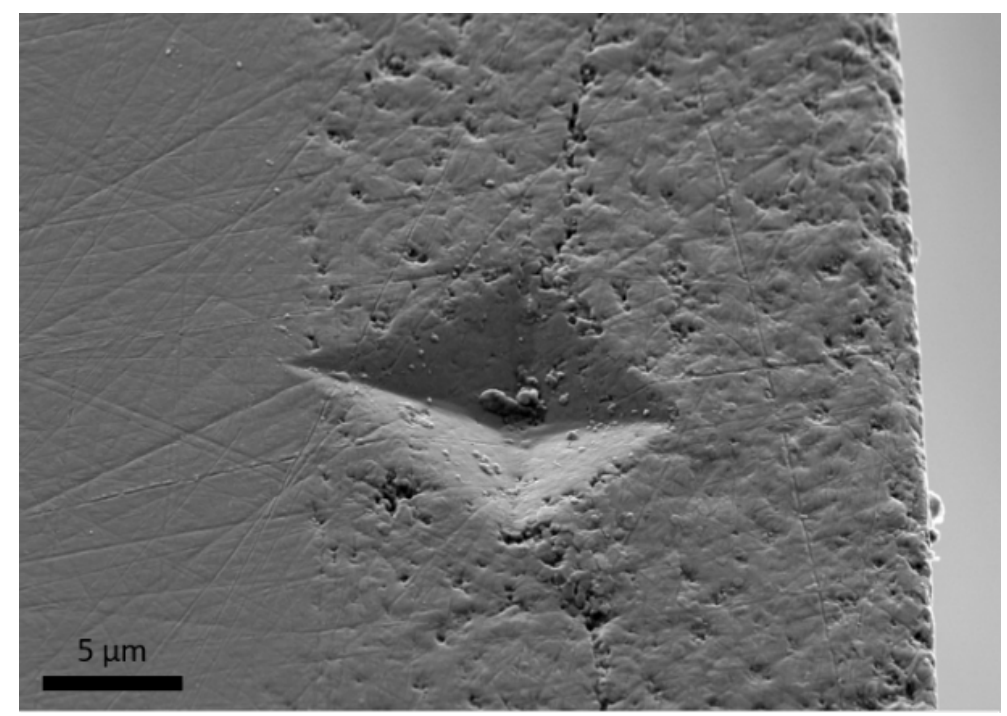

Fig. 7. FE-SEM micrograph of the imprint on the affected zone of the 3Y-TZP degraded material after $200 \mathrm{~h} \mathrm{LTD}$ exposure.

In the first step, trenches have been created with the FIB system, as shown in Figure 8. In Figure 8a, the degraded and non-degraded zones in this material can be clearly identified by the severe roughening that occurs in the degraded zone and increased porosity due to grain pull-out during sample preparation. Additionally, the imprint is located very close to the edge of the cross-section since degradation progresses from the surface inwards. A superimposed imprint-shaped element has been added in both images to show the size and location of the imprint edges since the material removal caused by the creation of the trench with the FIB eliminated a significant part of the imprint. The size of the imprints is considerably different between degraded and non-degraded material due to the loads applied. A higher load resulted in a bigger imprint, as can be seen in Figure $8 \mathrm{~b}$ for the non-degraded material. The reason for using different loads is to maintain a comparable crack length between both scenarios. 

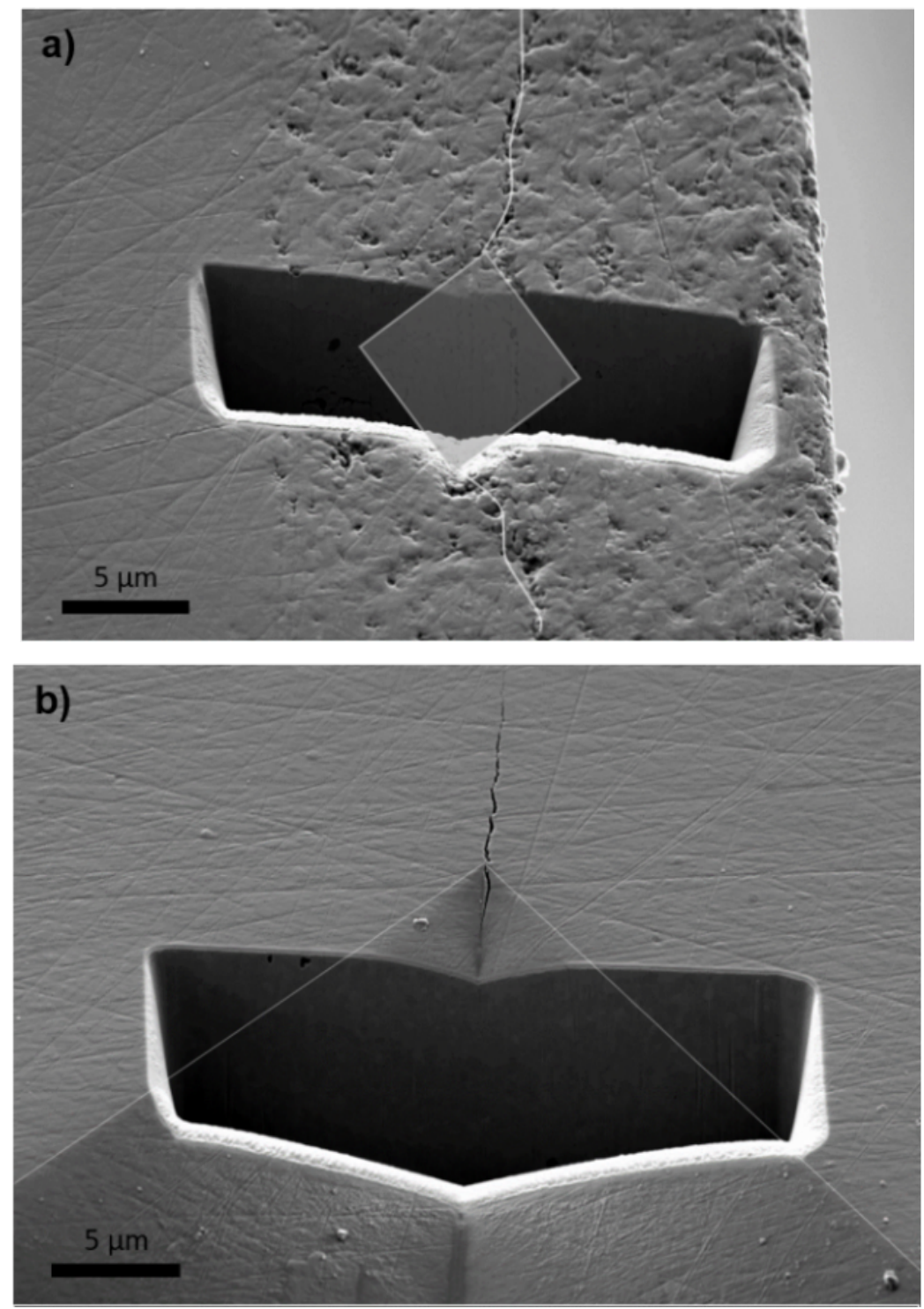

Fig. 8. FE-SEM micrographs of the trenches created with FIB technology on microindentation imprints for a) degraded and b) nondegraded 3Y-TZP material.

The crack propagation behavior is very different between degraded and non-degraded material. Figure 9 shows FE-SEM micrographs obtained with FIB of the sub-superficial cross-sections of degraded and non-degraded specimens as a sequence of frames, which have been numerated accordingly. In both cases, the initial frame corresponds to the cross-section at the farthest from the corner of the imprint and, hence, from the crack. At this point, no cracks are observed on the non-degraded material cross-section. However, the degraded material already results in a significant presence of cracks that propagate in 
several directions. This crack network remains present in all frames as the micrograph sequence moves towards the corner of the imprint. These cracks also present sharp turns and are not constrained to one single direction.
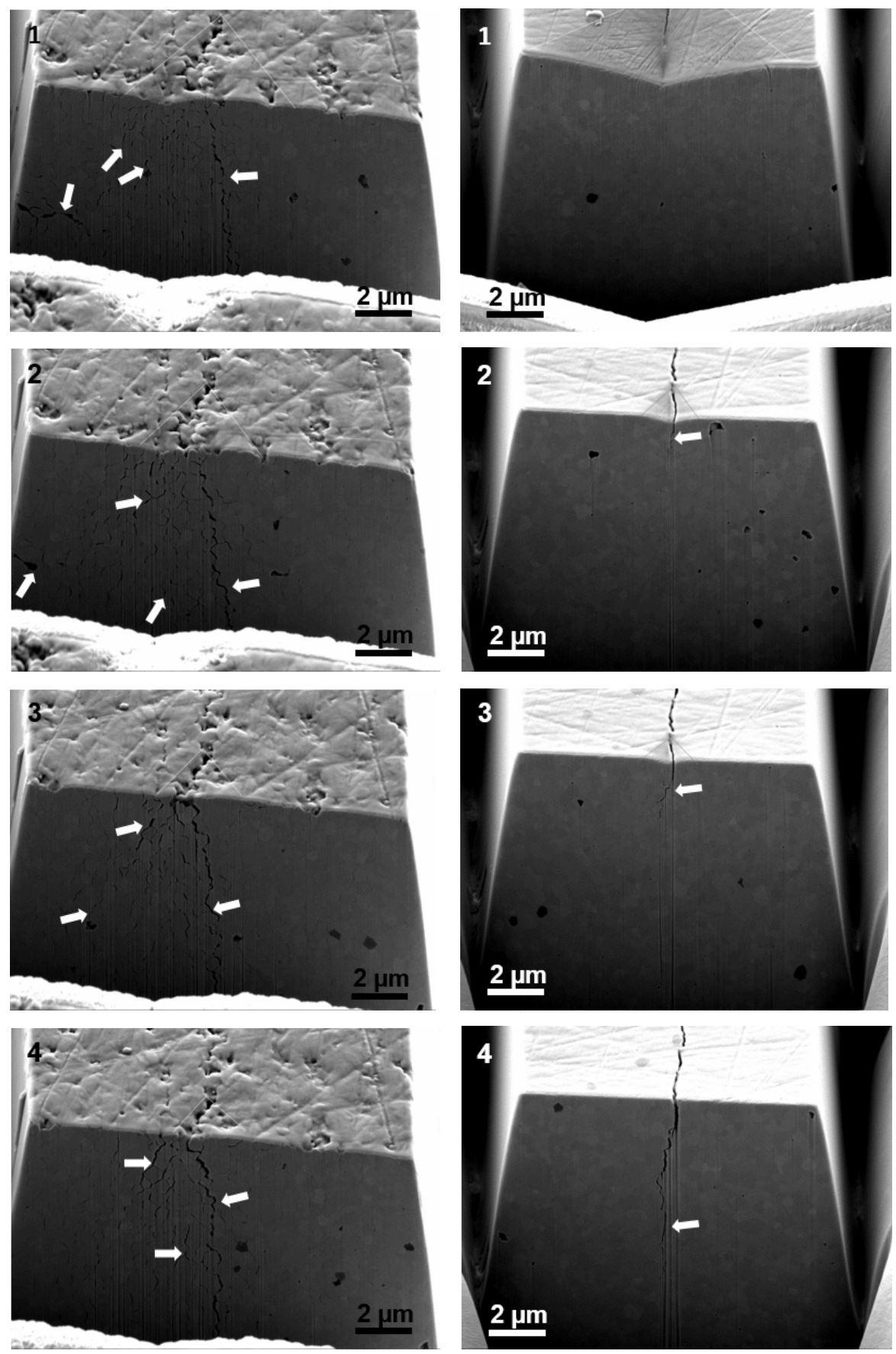

Fig. 9. FE-SEM micrographs of sub-superficial crack propagation in $3 Y-$ TZP degraded material after $200 \mathrm{~h}$ (left column) and non-degraded material (right column). 
In contrast, the crack behavior observed in non-degraded material suggest a Palmqvist crack behavior, characteristic of high fracture toughness materials. In this case, a welldefined, relatively straight crack appears in the second frame and propagates inwards. This frame is almost at the corner of the crack imprint. The third frame shows a slightly longer crack, which is even closer to the imprint corner. And finally, the fourth frame, which is taken after the corner of the imprint has been surpassed, the crack is significantly longer but remains constrained to one single direction instead of the crack network in several directions observed in the degraded material. The underlying cracks at the different corners of the imprint do not seem to be connected corresponding to the behavior observed in Palmqvist cracks. In contrast, the micrographs obtained on the degraded material indicate that the crack network below the imprint could be connected to the different cracks emerging from the corners of the indentation imprint.

\section{CONCLUSIONS}

Zirconia-containing composites have been successfully consolidated by a nonconventional processing technique: microwave sintering. Processing time and consumed energy have been reduced due to the dielectric heating mechanism involved in microwave-material interaction, which consists on the direct absorption of energy by the material, reducing convective and conductive heat losses that are present in conventional sintering methods. Additionally, the densification reached with microwave sintering is comparable to that obtained with conventional methods, in some case, at lower dwell temperatures, further reducing the energy consumption of the overall process. The resulting mechanical properties reach typical values for these materials. An improvement in this rubric cannot be established since the values compared to conventional sintering are very similar. Smaller zirconia grain sizes have also been obtained with microwave 
sintering due to faster heating rates and shorter dwell times. Also, microwave sintering has an important effect in the behavior of 3Y-TZP materials against LTD because it has a significant influence on the resulting microstructure of 3Y-TZP sintered ceramics and, hence, on their hydrothermal degradation susceptibility. Such behavior can be attributed to a lower c-phase content, which results from employing lower sintering temperatures with microwave heating in zirconia-only ceramics. This phase is responsible for depriving t-grains from stabilizer and making them more vulnerable to degradation. In the 3Y-TZP material sintered via microwave, the presence of m-phase was almost nonexistent even after $200 \mathrm{~h}$ of exposure to LTD conditions and the initial mechanical properties have been maintained. With the aid of FIB technology, the different cracking behaviors observed in degraded and non-degraded 3Y-TZP dental ceramics have been confirmed. It has also been possible to highlight the importance of increasing the resistance to LTD in order to decrease the probability of mechanical failure.

\section{ACKNOWLEDGEMENTS}

This work has been supported by the Spanish Ministry of Economy and Competitiveness MINECO (project MAT2015-67586-C3-R). The authors acknowledge to CAPESPrograma Ciências sem Fronteiras (Brazil) for the concession of a PVE project No. A086/2013. A. Presenda acknowledges the Generalitat Valenciana for his Santiago Grisolía scholarship (GRISOLIA/2013/035). A. Borrell acknowledges the MINECO for her Juan de la Cierva-Incorporación contract (IJCI-2014-19839).

\section{REFERENCES}

[1] C. Piconi, G. Maccauro, Zirconia as a ceramic biomaterial, Biomaterials. 20 (1999) $1-25$.

[2] B.D. Ratner, A.S. Hoffman, F.J. Schoen, J.E. Lemons, Biomaterials Science, 
Biomater. Sci. (2013).

[3] R.M. Mcmeeking, A.G. Evans, Mechanics of Transformation-Toughening in Brittle Materials, J. Am. Ceram. Soc. 65 (1982) 242-246.

[4] S. Biamino, P. Fino, M. Pavese, C. Badini, Alumina-zirconia-yttria nanocomposites prepared by solution combustion synthesis, Ceram. Int. 32 (2006) 509-513.

[5] J. Chevalier, S. Deville, E. Münch, R. Jullian, F. Lair, Critical effect of cubic phase on aging in 3 mol\% yttria-stabilized zirconia ceramics for hip replacement prosthesis, Biomaterials. 25 (2004) 5539-5545.

[6] J. Chevalier, B. Cales, J.M. Drouin, Low-Temperature Aging of Y-TZP Ceramics, J. Am. Ceram. Soc. 82 (1999) 2150-2154.

[7] V. Lughi, V. Sergo, Low temperature degradation -aging- of zirconia: A critical review of the relevant aspects in dentistry, Dent. Mater. 26 (2010) 807-820.

[8] M.E. Roy, L.A. Whiteside, B.J. Katerberg, J.A. Steiger, Phase transformation, roughness, and microhardness of artificially aged yttria- and magnesia-stabilized zirconia femoral heads., J. Biomed. Mater. Res. A. 83 (2007) 1096-102.

[9] J. Chevalier, L. Gremillard, S. Deville, Low-temperature degradation of zirconia and implications for biomedical implants, Annu.Rev.Mater.Res. 37 (2007) 1-32.

[10] A. Paul, B. Vaidhyanathan, J.G.P. Binner, Hydrothermal aging behavior of nanocrystalline Y-TZP ceramics, J. Am. Ceram. Soc. 94 (2011) 2146-2152.

[11] L. Gremillard, J. Chevalier, T. Epicier, S. Deville, G. Fantozzi, Modeling the aging kinetics of zirconia ceramics, J. Eur. Ceram. Soc. 24 (2004) 3483-3489.

[12] A. Goldstein, N. Travitzky, A. Singurindy, M. Kravchik, Direct microwave sintering of yttria-stabilized zirconia at $2.45 \mathrm{GHz}$, J. Eur. Ceram. Soc. 19 (1999) 2067-2072.

[13] S. Bodhak, S. Bose, A. Bandyopadhyay, Densification study and mechanical properties of microwave-sintered mullite and mullite-zirconia composites, J. Am. Ceram. Soc. 94 (2011) 32-41.

[14] E.T. Thostenson, T.-W. Chou, Microwave processing: fundamentals and applications, Compos. Part A Appl. Sci. Manuf. 30 (1999) 1055-1071.

[15] M. Oghbaei, O. Mirzaee, Microwave versus conventional sintering: A review of fundamentals, advantages and applications, J. Alloys Compd. 494 (2010) 175-189.

[16] A. Borrell, M.D. Salvador, F.L. Peñaranda-Foix, J.M. Cátala-Civera, Microwave sintering of zirconia materials: Mechanical and microstructural properties, Int. J. Appl. Ceram. Technol. 10 (2013) 313-320. 
[17] A. Borrell, M.D. Salvador, E. Rayón, F.L. Peñaranda-Foix, Improvement of microstructural properties of 3Y-TZP materials by conventional and nonconventional sintering techniques, Ceram. Int. 38 (2012) 39-43.

[18] Y. Ai, X. Xie, W. He, B. Liang, W. Chen, Microstructure and properties of $\mathrm{Al}_{2} \mathrm{O}_{3}$ $\mathrm{ZrO}_{2}$ ceramics prepared by microwave sintering, Key Eng. Mater. 633 (2014) 193197.

[19] R. Benavente, M.D. Salvador, F.L. Penaranda-Foix, E. Pallone, A. Borrell, Mechanical properties and microstructural evolution of alumina-zirconia nanocomposites by microwave sintering, Ceram. Int. 40 (2014) 11291-11297.

[20] Á. Presenda, M.D. Salvador, F.L. Peñaranda-Foix, R. Moreno, A. Borrell, Effect of microwave sintering on microstructure and mechanical properties in Y-TZP materials used for dental applications, Ceram. Int. 41 (2015) 7125-7132.

[21] E. Rayon, R. Moreno, C. Alcázar, M.D. Salvador, F.J. Manjõn, E. Jiménez-Piqué, et al., Enhanced hydrothermal resistance of Y-TZP ceramics through colloidal processing, J. Am. Ceram. Soc. 96 (2013) 1070-1076.

[22] A. Borrell, M.D. Salvador, M. Miranda, F.L. Peñaranda-Foix, J.M. Cátala-Civera, Microwave technique: A powerful tool for sintering ceramic materials, Curr. Nanosci. 10 (2014) 32-35.

[23] C.S. Lim, T.R. Finlayson, F. Ninio, J.R. Griffiths, In-situ measurement of the stress-induced phase transformations in magnesia-partially-stabilized zirconia using Raman spectroscopy, J. Am. Ceram. Soc. 75 (1992) 1570-1573. 


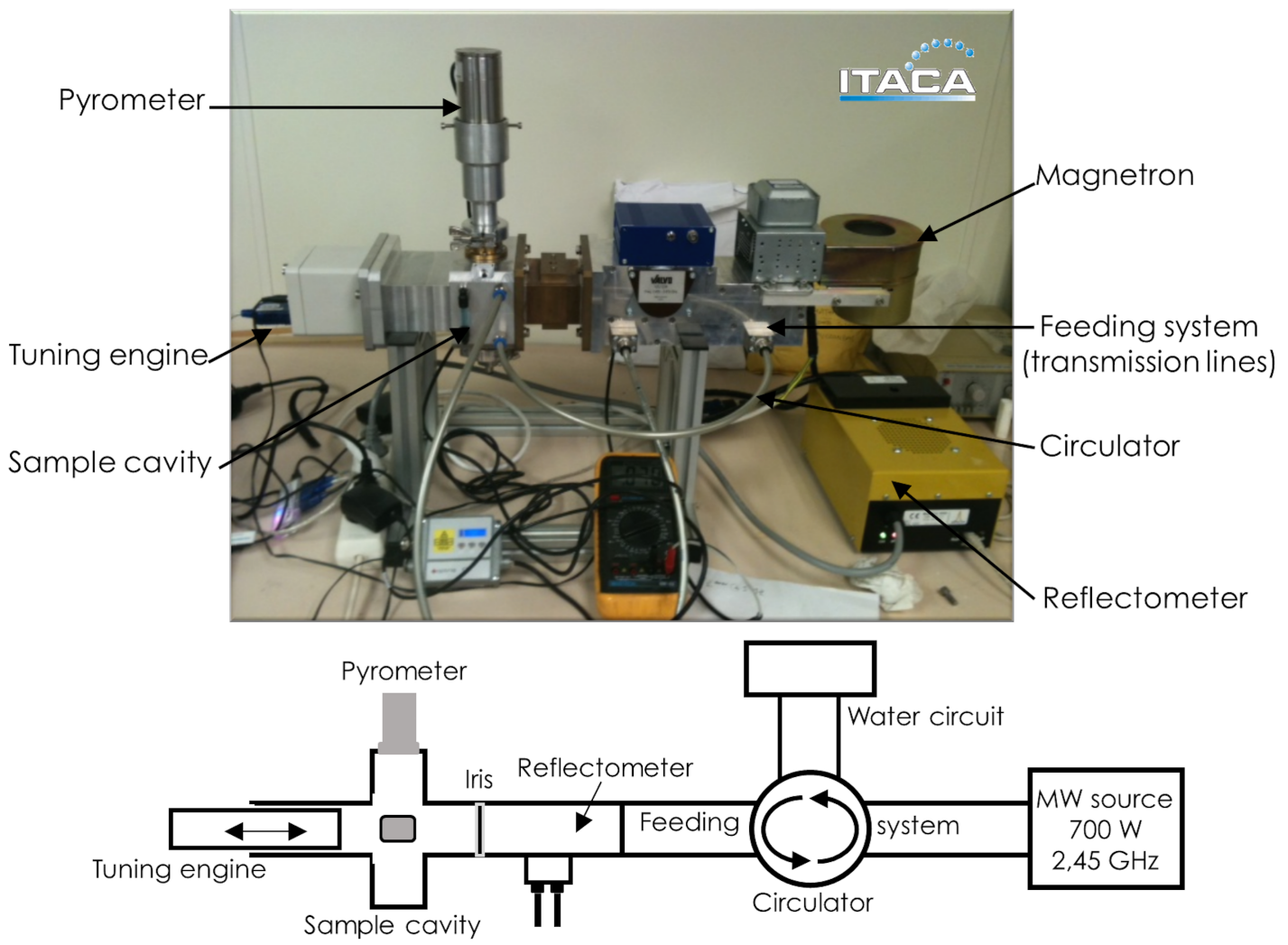



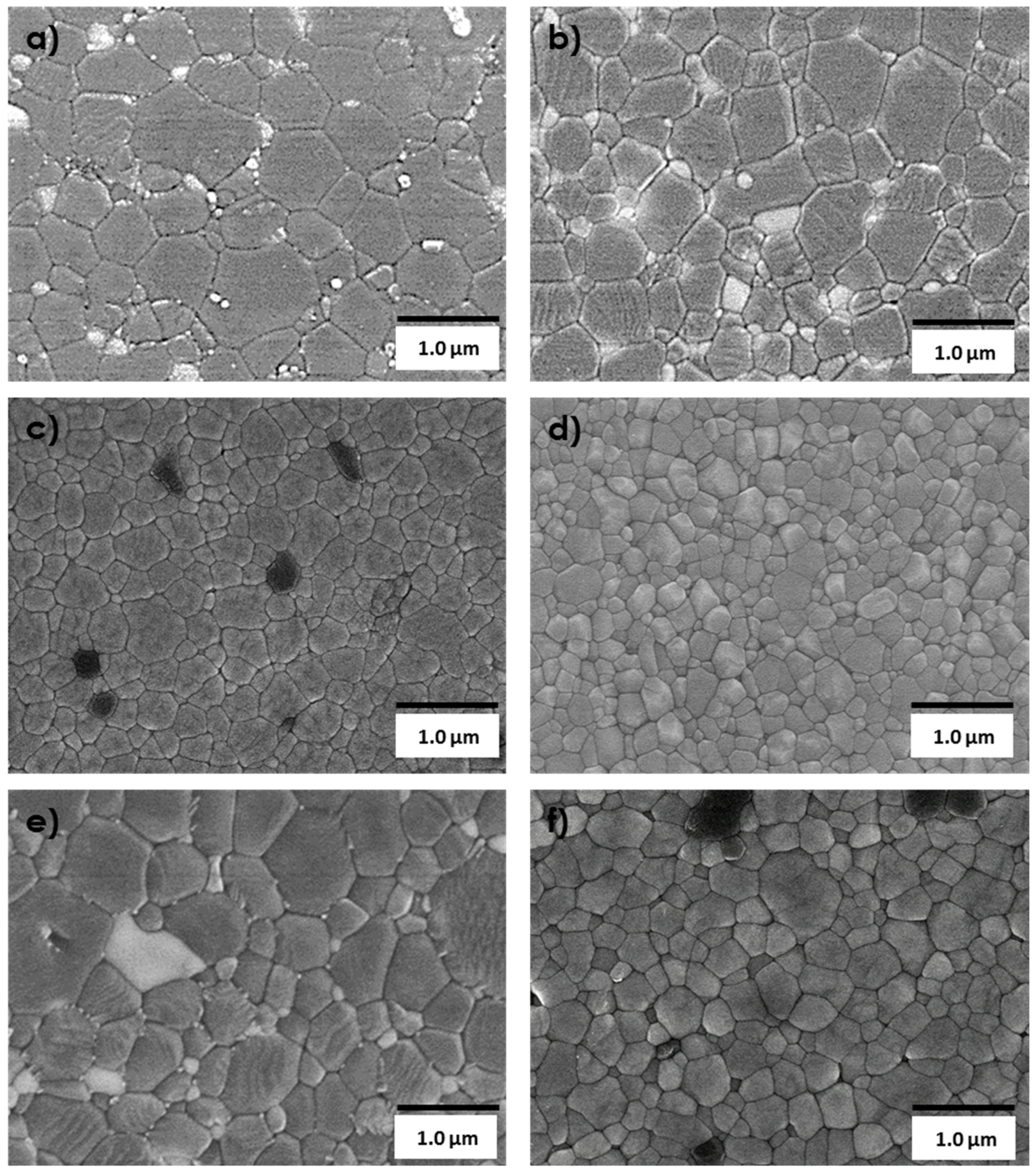


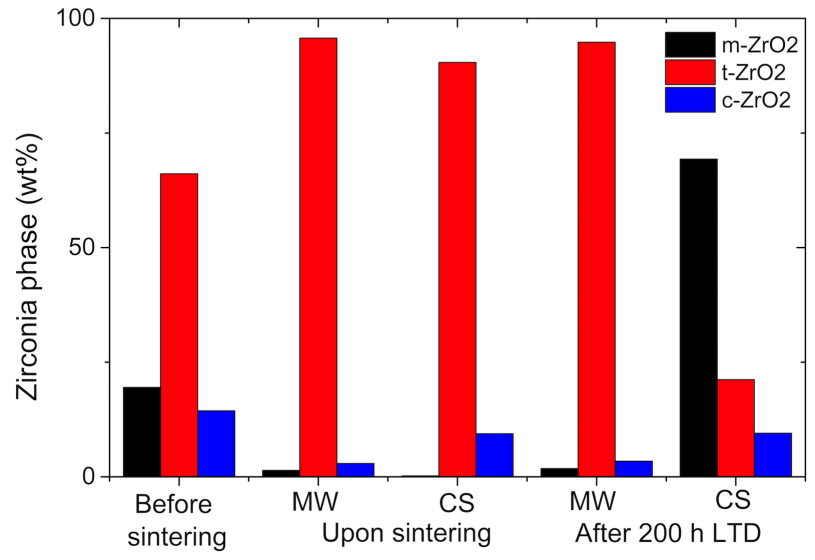




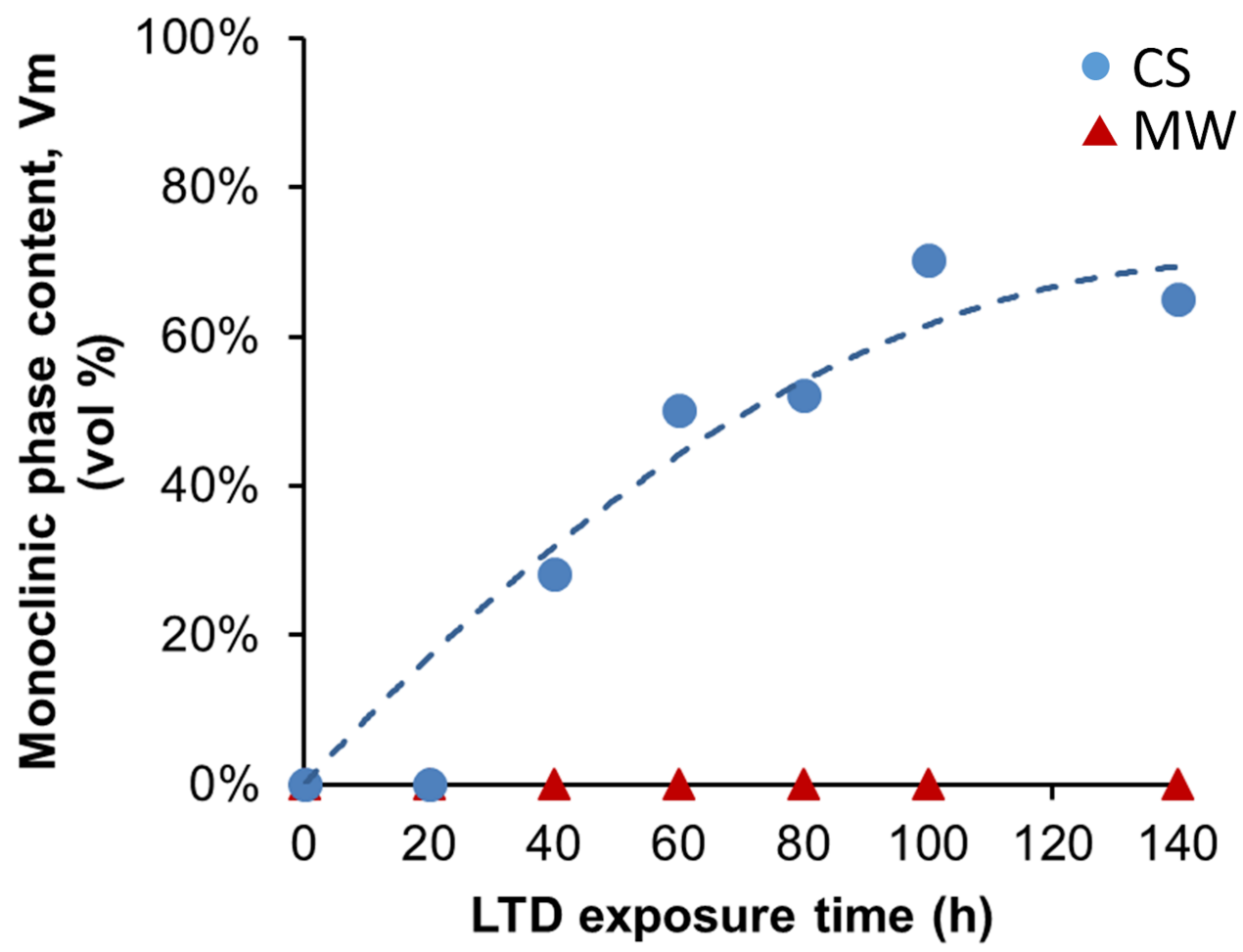


a)

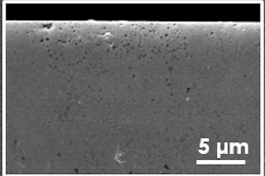
Degraded zone (depth 5 pm)

b)

Non-affected zone

(4)

$20 \mu \mathrm{m}$

,
Degradea zone

(depth $=14 \pm 3 \mu \mathrm{m}$ )

Non-affected zone

(3)

$20 \mathrm{\mu m}$




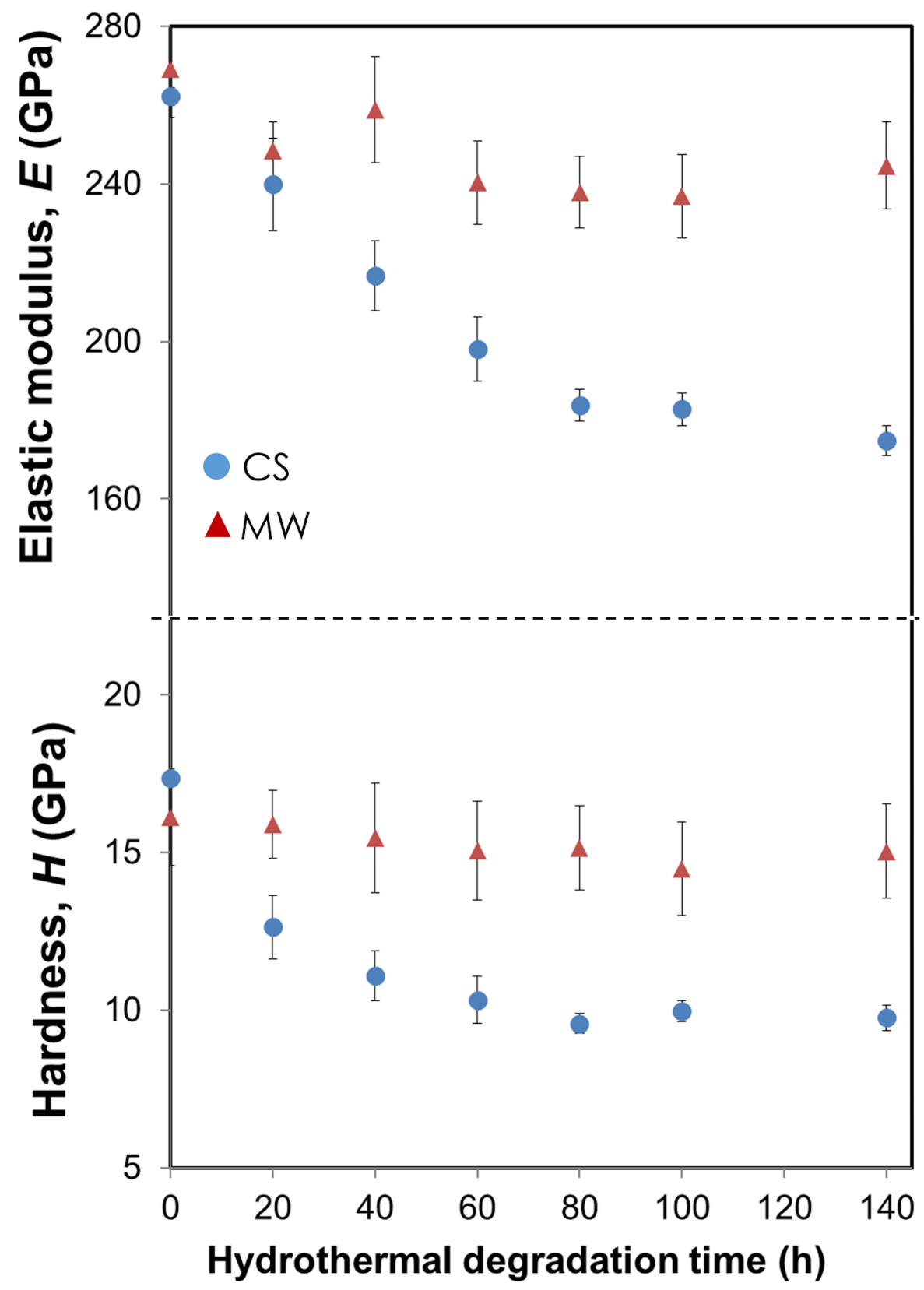




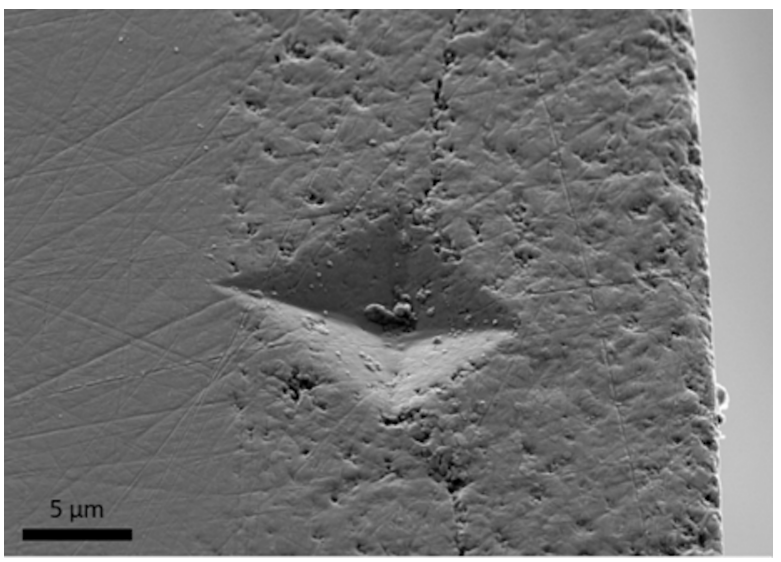


a)

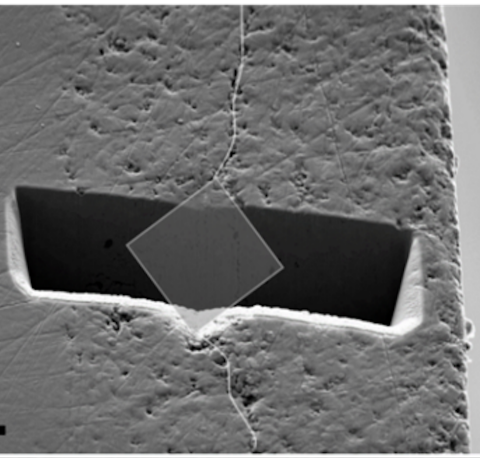

b)

$5 \mu \mathrm{m}$

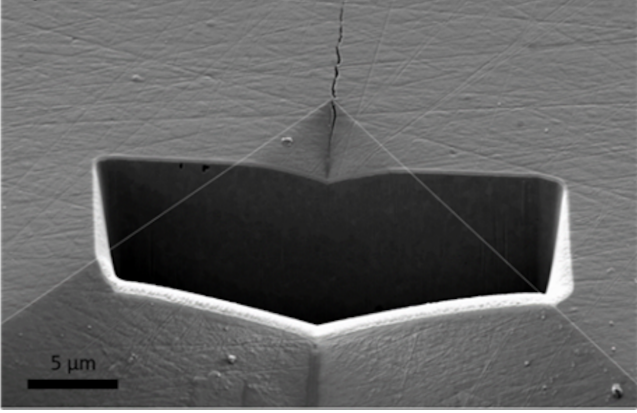



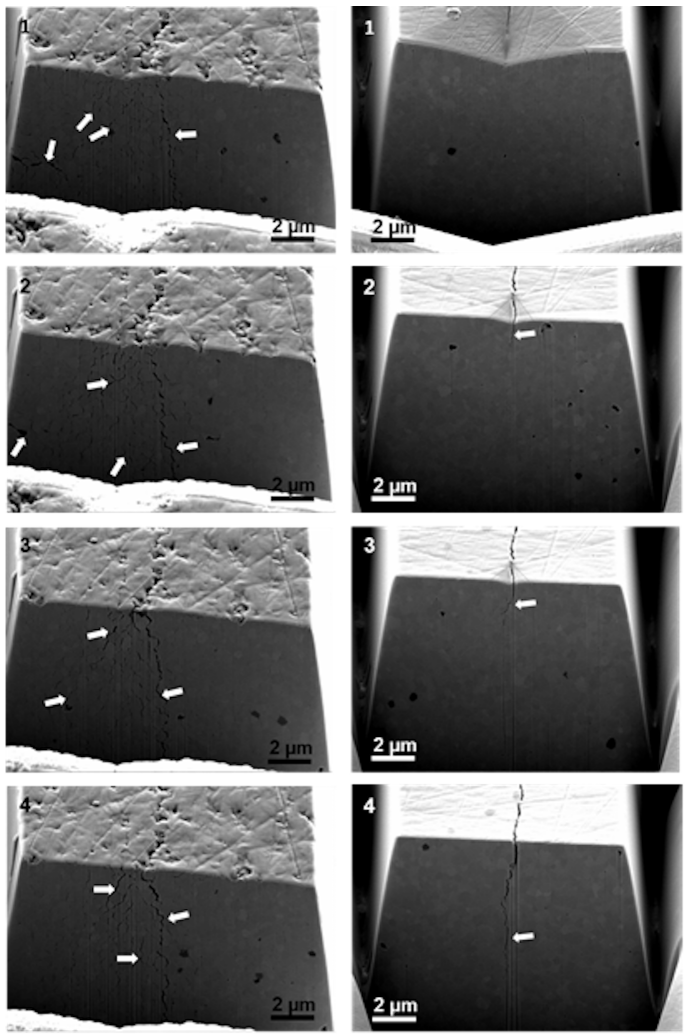
Table 1. Sintering conditions, density and mechanical properties obtained for the ZTA and ATZ composites and 3Y-TZP materials under different sintering conditions.

\begin{tabular}{|c|c|c|c|c|c|c|}
\hline Material & $\begin{array}{l}\text { Sintering } \\
\text { method }\end{array}$ & $\begin{array}{c}\text { Sintering } \\
\text { temperature } \\
\left({ }^{\circ} \mathrm{C}\right)\end{array}$ & $\begin{array}{l}\text { Dwell } \\
\text { time } \\
\text { min }\end{array}$ & $\begin{array}{c}\text { Density } \\
(\%)\end{array}$ & $\begin{array}{c}\text { Vickers } \\
\text { hardness } \\
\text { (GPa) }\end{array}$ & $\begin{array}{c}\text { Fracture } \\
\text { toughness } \\
\left(\mathrm{MPa} \cdot \mathrm{m}^{1 / 2}\right)\end{array}$ \\
\hline \multirow{3}{*}{$15 \mathrm{ZTA}$} & \multirow{2}{*}{ MW } & 1300 & 10 & $96.4 \pm 0.5$ & $13.1 \pm 1.0$ & $5.2 \pm 0.5$ \\
\hline & & 1400 & 10 & $98.9 \pm 0.4$ & $17.9 \pm 0.7$ & $5.9 \pm 0.4$ \\
\hline & $\mathrm{CS}$ & 1400 & 120 & $98.3 \pm 0.4$ & $16.7 \pm 0.6$ & $6.1 \pm 0.3$ \\
\hline \multirow{3}{*}{$10 \mathrm{ZTA}$} & \multirow{2}{*}{ MW } & 1300 & 10 & $94.1 \pm 0.4$ & $14.1 \pm 0.8$ & $4.3 \pm 0.5$ \\
\hline & & 1400 & 10 & $99.2 \pm 0.5$ & $19.8 \pm 0.5$ & $5.3 \pm 0.4$ \\
\hline & $\mathrm{CS}$ & 1400 & 120 & $98.2 \pm 0.5$ & $19.6 \pm 0.6$ & $5.6 \pm 0.3$ \\
\hline \multirow{3}{*}{$5 \mathrm{ZTA}$} & \multirow{2}{*}{ MW } & 1300 & 10 & $92.4 \pm 0.4$ & $12.6 \pm 0.9$ & $4.0 \pm 0.5$ \\
\hline & & 1400 & 10 & $98.9 \pm 0.3$ & $19.3 \pm 0.5$ & $4.4 \pm 0.4$ \\
\hline & $\mathrm{CS}$ & 1400 & 120 & $98.6 \pm 0.3$ & $19.1 \pm 0.6$ & $3.3 \pm 0.3$ \\
\hline \multirow{3}{*}{$5 \mathrm{ATZ}$} & \multirow{2}{*}{ MW } & 1300 & 10 & $95.5 \pm 0.5$ & $12.7 \pm 0.7$ & $6.9 \pm 0.5$ \\
\hline & & 1400 & 10 & $98.5 \pm 0.4$ & $13.2 \pm 0.6$ & $6.2 \pm 0.6$ \\
\hline & $\mathrm{CS}$ & 1400 & 120 & $99.5 \pm 0.4$ & $13.8 \pm 0.5$ & $6.9 \pm 0.5$ \\
\hline \multirow{3}{*}{ 3Y-TZP } & \multirow{2}{*}{ MW } & 1200 & 10 & $99.5 \pm 0.5$ & $13.9 \pm 0.8$ & $6.6 \pm 0.4$ \\
\hline & & 1300 & 10 & $99.3 \pm 0.5$ & $14.7 \pm 0.6$ & $5.8 \pm 0.4$ \\
\hline & $\mathrm{CS}$ & 1400 & 120 & $99.1 \pm 0.5$ & $13.9 \pm 0.4$ & $6.5 \pm 0.5$ \\
\hline
\end{tabular}




\section{Highlights:}

- Fully-densified zirconia-based ceramics can be obtained with microwave sintering.

- Microwave heating processing reduces time and energy consumption.

- Microwave sintering can enhance the resistance to LTD of Y-TZP ceramics.

- LTD results in extended crack propagation due to loss of fracture toughness. 